\title{
Reflexiones sobre la función constitucional de la oposición política en el ordenamiento mexicano*
}

Héctor Fix-Zamudio

\section{Introducción}

1. He elegido este importante tema debido a su actualidad en el ordenamiento mexicano, en cuanto las sucesivas reformas electorales han propiciado el pluralismo político y el fortalecimiento de los partidos de oposición, por lo que es conveniente realizar un análisis sobre la evolución constitucional de los derechos de la oposición en nuestro país.

2. Sobre los aspectos políticos de la participación de la oposición en los gobiernos de la democracia liberal ${ }^{1}$ se han elaborado numerosos estudios entre los cuales destacan la clásica obra de Robert Dahl ${ }^{2}$ y el artículo también clásico de Pedro de Vega García ${ }^{3}$, pero en cambio no han sido tan abundantes los análisis desde el enfoque estricta o predominantemente jurídico, aun cuando en los últimos años se han elaborado algunos trabajos que se refieren de manera específica a esta materia, entre los cuales podemos señalar de manera especial los de Giuseppe de Vergottini ${ }^{4}$ y de Juan Fernando López Aguilar. ${ }^{5}$

* Publicado en Memoria de El Colegio Nacional, México, 1999, pp. 67-100.

1 Pablo Lucas Verdú y Pablo Lucas Murillo de la Cueva, "Manual de Derecho Politico", Volumen primero Introducción y Teoria del Estado. $2^{\circ}$ ed. Madrid, Tecnos, 1990, pp. 293-297.

2 Political Opposition in Western Democracies, Yale University Press, 1966.

3 "Para una teoría política de la oposición", en su libro Estudios político-constitucionales, México, UNAM, 1987, pp. 9-445.

4 "Opposizione parlamentare", en Enciclopedia del Diritto, tomo XXX, Milán, Giuffré, 1980, pp. 532-561; y "La garanzia della funzione di opposizione como elemento unificante delle forme di governo", en su libro Diritto costituzionale comparato, $4^{\text {a }}$. ed., Padua, Cedam, 1993, pp. 403-417. 
3. Por el contrario, no ha existido una preocupación similar en los constitucionalistas latinoamericanos, incluidos los mexicanos, para examinar de manera especial esta cuestión, pues la mayoría de los estudios se han dirigido al examen de la regulación de los partidos políticos y de los sistemas electorales, sobre los cuales existe una amplia bibliografía, pero no respecto de los análisis de la función constitucional de la oposición. Como ejemplos significativos podemos señalar los recientes estudios colectivos editados el primero por el conocido estudioso alemán Dieter Nohlen ${ }^{6}$ y el segundo coordinado por el mismo Dieter Nohlen con la colaboración de Sonia Picado y Daniel Zovatto ${ }^{7}$.

4. Por ello, considero conveniente realizar un análisis preliminar de esta materia de gran trascendencia en la evolución reciente de los regímenes constitucionales latinoamericanos, en los cuales se advierte un creciente pluralismo con posterioridad a la superación de los regímenes autoritarios, la mayoría de ellos de carácter castrense, que predominaron en nuestra región en las décadas de los setentas y de los ochentas. Algunos de los nuevos ordenamientos constitucionales que se expidieron a partir de la Ley Fundamental de Guatemala de 1985, han establecido una regulación progresiva de los partidos políticos y de los sistemas electorales, y algunos de ellos como lo señalaré más adelante, han establecido normas específicas para la función de la oposición, tanto dentro de las cámaras legislativas como en las actividades extraparlamentarias de los partidos y grupos políticos. (Ver infra párrafo 22).

\section{Institucionalización constitucional de los partidos políticos}

5. Si bien existió la preocupación de la mayoría de las constituciones de los países que adoptaron la democracia liberal de regular jurídicamente a los partidos políticos modernos surgidos de acuerdo con el ejemplo de las costumbres y convenciones del derecho inglés ${ }^{8}$, en la mayoría

5 Minoria y oposición en el parlamentarismo. Una aproximación comparativa, Madrid, Publicaciones del Congreso de los Diputados, 1991.

6 Elecciones y sistemas de partidos en América Latina, San José, Costa Rica, Instituto Interamericano de Derechos Humanos, 1993.

7 Tratado de derecho electoral comparado de América Latina, México, FCE, 1998.

8 Cfr. Dicey, A.B., Introduction to the Study of the Law of the Constitution, $10^{\mathrm{a}}$. ed., London, The Macmillan Press, reimpresión, 1979, pp. 270-286. 
de los casos esta regulación se efectuó por medio de leyes electorales, pero en la segunda posguerra se inició una tendencia progresiva hacia la constitucionalización de los partidos políticos, ya que en numerosos textos constitucionales se establecen los lineamientos esenciales que regulan el reconocimiento así como los derechos y obligaciones de los partidos políticos.

6. En esta dirección podemos señalar en Europa occidental a las Leyes Fundamentales de la República Federal de Alemania (1949), artículo $21^{\circ}$; de España (1978), artículo $6^{\circ}$; de Francia (1958), artículo $4^{\circ}$; de Italia (1948), artículo $49^{\circ}$; y de Portugal (1976-1982), artículo $117^{\circ}$. Por lo que respecta a los ordenamientos latinoamericanos, en la mayoría de los casos con normas más amplias que las europeas, destacamos las Constituciones de Argentina (1853-1860, en su texto reformado en

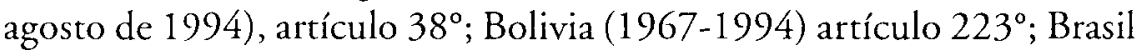
(1988), artículo $17^{\circ}$; Chile (1980-1989), artículo $19^{\circ}$, fracción 15; Colombia (1991), artículos $107^{\circ}-111^{\circ}$; Costa Rica (1949-1989), artículo $98^{\circ}$; Ecuador (1978, texto reformado en 1996 y 1998), artículos $114^{\circ}$ $118^{\circ}$; El Salvador (1983, texto reformado en 1991), artículo 85 ; Haití (1987), artículo $31^{\circ}$, inciso 1 ; Honduras (1982), artículos $47^{\circ}-50^{\circ}$; México (1917, reformas de 1977, 1993 y 1996), artículo 41ㅜ Panamá (1972-1983), artículo $132^{\circ}$; Paraguay (1992), artículos $124^{\circ}-125^{\circ}$; Perú (1993), artículo $35^{\circ}$; República Dominicana (1994), artículo 104\%; Uruguay (1967, reforma de 1996), artículo $77^{\circ}$, inciso 11; Venezuela (1961), artículo $114^{\circ}$.

7. De la larga enumeración anterior, que no pretende ser exhaustiva, se puede observar que la tendencia hacia la regulación constitucional de los partidos políticos es cada vez más extensa en el derechn comparado. Sería imposible hacer referencia a cada uno de estos ordenamientos, pero en un examen de conjunto podemos señalar que en la mayoría de los preceptos fundamentales señalados en el párrafo anterior se establece un mínimo de requisitos para el registro oficial de los partidos políticos, así como de sus programas y estructura interna. Algunas de estas normas señalan que los partidos políticos deben respetar los valores de los regímenes democráticos en los cuales deben operar y por lo tanto no se admiten programas que postulen principios contrarios a la soberanía y a la propia democracia, y en ciertos preceptos se prohibe que establezcan como principios el uso de la violencia o la organización paramilitar. Varios preceptos fundamentales disponen expresamente que la organi- 
zación interna de los partidos políticos debe ser democrática, y en esta dirección es posible señalar a las Constituciones de la República Federal de Alemania, Portugal, Argentina, Brasil, Chile, El Salvador, Paraguay, Perú, Uruguay y Venezuela, entre otros.

8. En general se prohibe la existencia de partidos en cuyos principios se encuentran los de subvertir el orden democrático, y en el caso de la República Federal de Alemania, debido al doloroso recuerdo del nacionalsocialismo, y la existencia de algunos grupos minoritarios que postulaban ideas similares a las del gobierno totalitario de Hitler, se estableció la prohibición de los partidos inconstitucionales (artículo $21^{\circ}$, inciso 2), y se confió al Tribunal Federal Constitucional la declaración respectiva. De acuerdo con esta disposición, el citado Tribunal Federal Constitucional dispuso la disolución del Partido Socialista del Reich, de carácter neonazi, según fallo de 23 de octubre de 1952, así como del Partido Comunista Alemán, que postulaba ideas stalinistas, por sentencia de 17 de agosto de 1956. A partir de entonces los pequeños partidos o grupos políticos de extrema derecha o de izquierda se han sometido a las reglas fundamentales. ${ }^{9}$

9. Aun cuando existe variedad en las normas constitucionales que regulan los partidos políticos, algunas de ellas establecen los derechos de los partidos políticos registrados (que en otros ordenamientos se regulan por leyes ordinarias) a acceder a los medios de comunicación y a divulgar sus programas, y además a recibir financiamiento público, en proporción a su fuerza electoral, con el fin de evitar que se concentren en algunos de ellos recursos económicos provenientes de grandes corporaciones o del extranjero. El problema del financiamiento de los partidos políticos es uno de los más complicados y ha dado lugar a disposiciones legales muy complejas que a pesar de sus esfuerzos, no han podido resolver definitivamente la cuestión. ${ }^{10}$

9 Cfr. Dieter Grimm, "Los partidos políticos", en el libro Manual de Derecho Constitucional, trad. de Inter-Nationes, de Bonn, Madrid, Instituto Vasco de Administración Pública-Marcial Pons, 1996, pp. 389-444.

10 Cfr. Instituto de Investigaciones Jurídicas. Aspectos juridicos del financiamiento de los partidos politicos, México, UNAM, 1993, y La financiación politica en lberoamérica, editado por Pilar del Castillo y Daniel Zovatto, San José, Costa Rica, Instituto Iberoamericano de Derechos Humanos-Capel, 1998. Petra Blendel, "Los partidos políticos: condiciones de inscripción y reconocimiento legal, democracia interna, etcétera", en Tratado de derecho electoral comparado de América Latina, cit. supra nota 7, pp. 384-409. 
10. Otro aspecto importante para el funcionamiento de los partidos políticos en un régimen de pluralismo, se apoya en los regímenes electorales, ya que en los países que han servido de modelo histórico a los ordenamientos latinoamericanos, es decir, Inglaterra, algunos ordenamientos de la Commonwealth, como Canadá, Australia y Nueva Zelandia, así como los Estados Unidos, han seguido el sistema de mayoría relativa, lo que favorece a los partidos de mayor importancia y por ello también al bipartidismo que se ha impuesto en estos países. Por supuesto que este sistema no es adecuado para los incipientes partidos latinoamericanos, debilitados por los numerosos años de regímenes autoritarios, y por ello se han impuesto recientemente los diversos modelos de representación proporcional, por lo que, ha dado lugar, en la mayoría de los casos, a la implantación de sistemas de carácter mixto. ${ }^{11}$

11. Otro sector que merece destacarse es la tendencia cada vez más evidente hacia la judicialización de los conflictos electorales, que tradicionalmente se consideraban como ajenos a la intervención de los tribunales, por tratarse una cuestión estrictamente política. Podemos citar como ejemplo la jurisprudencia tradicional del derecho constitucional norteamericano, que estimaba la materia electoral como una political question: y por tanto ajena a la competencia de los tribunales, en particular de la Corte Suprema Federal, ${ }^{12}$ pero ese criterio se modificó de manera paulatina para considerar como justiciables cuestiones que anteriormente se consideraban de naturaleza política en sentido estricto, como las electorales, aun cuando siempre por conducto de una controversia judicial. En esta dirección se cita el caso Baker contra Carr resuelto en 1962, como el que inició este desarrollo. ${ }^{13}$

11 Cfr. Instituto de Investigaciones Jurídicas, Tendencias contemporáneas del derecho electoral en el mundo. Memoria del II Congreso Internacional de Derecho Electoral, México, UNAM, 1993, esp. pp. 207-448, que contienen los estudios que se refieren de manera específica a los sistemas electorales.

12 Cfr. Bernard Schwartz, Los poderes del gobierno. Comentario sobre la Constitución de los Estados Unidos, trad. de José Juan de Olloqui Labastida, México, UNAM, 1966, t. I, pp. 576-579; Charles Evans Hughes, La Suprema Corte de los Estados Unidos, trad. de Roberto Molina Pasquel y Vicente Herrero, 2a . ed., México, FCE, 1971, pp. 56-58; Enrique Alonso García, «El Tribunal Burger y la doctrina de las "Political Questions" en Estados Unidos», en Revista Española de Derecho Constitucional, núm. 1, enero-febrero de 1964 , pp. 5-39.

13 Cfr. Karl Loewenstein, "La función política del Tribunal Supremo de los Estados Unidos», en Revista de Estudios Políticos, núm. 133, Madrid, enero-febrero de 
12. En efecto, en los últimos años se ha atribuido de manera creciente a órganos autónomos de carácter administrativo, o inclusive a tribunales ordinarios o especializados, con predominio de estos últimos, la solución de los conflictos de carácter electoral, con lo cual ha surgido desde el punto de vista doctrinal una disciplina reciente que puede calificarse como "derecho procesal electoral» ${ }^{14}$. Para citar únicamente algunos ejemplos latinoamericanos, un modelo contencioso judicial encomendado a tribunales ordinarios especializados, es el establecido en el régimen constitucional brasileño, en el cual a partir de la Carta Federal de 1934 (y con exclusión de la Constitución autoritaria de 1937), se estableció una verdadera jurisdicción electoral, integrada por jueces y tribunales especializados para conocer y decidir las controversias surgidas en los procedimientos electorales. El artículo $118^{\circ}$ de la Constitución brasileña vigente, promulgada el 5 de octubre de 1988, considera como órganos de la justicia electoral al Tribunal Superior, los tribunales regionales, los jueces y las juntas, todos ellos de carácter electoral. ${ }^{15}$

13. En varios ordenamientos constitucionales latinoamericanos se observa una orientación hacia el establecimiento de tribunales electorales especializados, pero de carácter autónomo, y en la mayoría de los casos independientes del poder judicial y de los otros órganos del Estado. En esta dirección es posible señalar, entre otros, la Corte Nacional Electoral de Bolivia, (Constitución de 1967-1994), artículo 225; el Tribunal Calificador de Elecciones y los tribunales regionales electorales de Chile, (Constitución de 1980-1989) artículos $84^{\circ}-85^{\circ}$; el Tribunal Supremo de Elecciones de Costa Rica, (Constitución de 1949-1989), artículos $99^{\circ}-104^{\circ}$; el Tribunal Supremo Electoral de Ecuador, (Constitución de 1978, texto de 1998), artículos $204^{\circ}-210^{\circ}$; el Tribunal Electoral de Panamá, (Constitución de 1972-1983), artículos $136^{\circ}-139^{\circ}$; el

1964, pp. 5-39. También puede consultarse el agudo comentario de Jack W. Peltason, sobre el citado caso "Baker v. Carr", en The Oxford Companion to the Supreme Court of the United States, New-York-London, 1992, pp. 56-59.

14 Cfr. Héctor Fix-Zamudio, "Introducción a la teoría de los recursos en el contencioso-electoral", en Manual sobre los medios de impugnación en el Código Federal de Instituciones y Procedimientos Electorales, México, Instituto Federal Electoral-UNAM, 1992, pp.6-9; Flavio Galván Rivera, Derecho procesal electoral mexicano, México, McGraw-Hill, 1997.

15 Cfr. José Afonso De Silva, Curso de derecho constitucional positivo, 9a. ed., $3^{2}$. reimp. Sâo Paulo, Malheiros Editores, 1993, pp. 497-498. 
Tribunal Superior de Justicia Electoral de Paraguay, (Constitución de 1992), artículos $273^{\circ}-279^{\circ}$ y la Corte Electoral de Uruguay, (Constitución de 1967), artículos $322^{\circ}-328^{\circ}{ }^{\circ}{ }^{16} \mathrm{La}$ introducción y el desarrollo de la jurisdicción electoral en México ha sido muy significativa como se señalará más adelante (ver infra párrafos 29-35).

14. Además de los anteriores, existen otros tribunales electorales que no están regulados constitucionalmente, como ocurre con los de Guatemala y de Honduras, y algunos consejos o jurados de elecciones, que tienen carácter mixto, pues además de sus facultades administrativas para organizar los sufragios, también conocen sobre conflictos electorales y deciden de manera definitiva sobre los resultados de la calificación respectiva, por lo que realizan funciones jurisdiccionales, por lo que generalmente se integran con jueces y magistrados como ocurre entre otras, en las legislaciones constitucionales de Colombia, El Salvador, Nicaragua, Perú, República Dominicana y Venezuela. ${ }^{17}$

\section{Institucionalización constitucional de la oposición}

15. Aun cuando varios de los instrumentos establecidos para la regulación de los partidos políticos en los textos fundamentales también están dirigidos para proteger los derechos de los grupos políticos minoritarios, como son las normas relativas al acceso a los medios de comunicación, el financiamiento público, los sistemas de representación proporcional, así como los órganos total o parcialmente jurisdiccionales, sin embargo se advierte, que de acuerdo con el ejemplo de Inglaterra y otros países de la Commonwealth, se ha manifestado la tendencia hacia

16 Cfr. Dieter Nohlen, (ed.), Elecciones y sistemas de partidos en América Latina, cit., supra nota 5; José de Jesús Orozco Henríquez, "Los sistemas de justicia electoral desde una perspectiva comparativa", en la obra Tendencias contemporáneas del derecho electoral en el mundo, cit. supra nota 11, pp. 793-826; Id. "Los sistemas contenciosos electorales en América Latina», en Justicia Electoral, México, vol. I, núm. 7, 1996, pp. 5-40; id. "El contencioso electoral. La calificación electoral", en Tratado de derecho electoral comparado de América Latina, cit. supra nota 7, pp. 708-807; Héctor Gros Espiell, La Corte Electoral del Uruguay, San José de Costa Rica, Instituto Interamericano de Derechos Humanos-Capel, 1990.

17 Cfr. Diego Valadés Ríos, Constitución y Politica, 2ª ed., México, UNAM, 1994, pp. $97-116$. 
el establecimiento de instrumentos que otorguen específicamente a la oposición el carácter de entidad constitucionalmente protegida.

16. Desde el punto de vista histórico, la llamada «disconformidad política» expresión de los sectores políticos contrarios a los órganos del gobierno, no fue reconocida, en un principio, ya que se marginó de manera sistemática a los opositores, pues durante el amplio desarrollo que parte de la antigüedad, pasa por la edad media y llega al renacimiento, no podía considerarse la existencia jurídica de una oposición, por el contrario predominó la tendencia de exclusión existencial del «enemigo". La oposición como tal surgió en la Inglaterra del siglo XVIII y tardó tiempo en reconocerse en los ordenamientos europeos continentales, debido a la influencia de las ideas de Juan Jacobo Rousseau sobre la voluntad general, y se consolidó en la democracia liberal, la que se encuentra estrechamente vinculada con la oposición como forma de disconformidad política. ${ }^{18}$

17. Por su parte, el distinguido constitucionalista italiano Giuseppe de Vergottini, señala tres etapas lógicas y no forzosamente históricas, en la evolución del concepto político y jurídico de la oposición: a) en primer término como «disentimiento", b) en segundo lugar como «límite», y c) finalmente como «alternativa»; de acuerdo con los regímenes políticos en los cuales se presenta. En cuanto al «disentimiento» se manifiesta en los gobiernos autoritarios, que en la época contemporánea se caracterizaron por partidos únicos, y por ello no aceptaron la posibilidad de grupos políticos diversos del que se encontraba en el poder, los que se consideraban inconstitucionales o ilegales, y por tanto eran reprimidos. Como «límite» se advierte en los gobiernos políticamente homogéneos, en los cuales tenía predominio el pensamiento de Juan Jacobo Rousseau sobre la voluntad general, que establecía una unanimidad ficticia, por lo que únicamente se toleraba la existencia de grupos minoritarios, concepción que evolucionó hacia la consolidación con el reconocimiento del mencionado principio mayoritario con la tutela de las minorías políticas. Finalmente, en el Estado liberal se reconoce a la oposición como una «alternativa» en el cambio del gobierno y por ello se establecen disposiciones constitucionales que la tutelan. Es esta última

18 Cfr. Graciela Soriano de García Pelayo, «La noción de oposición como expresión histórica de la disconformidad política", en Antario Juridico, XVIII, 1991. México, UNAM, 1992, pp. 147-171. 
etapa la que el profesor Vergottini califica como «oposición garantizada” terminología que ha tenido una excelente acogida en la doctrina contemporánea ${ }^{19}$.

18. El reconocimiento jurídico de la oposición como una entidad constitucional indispensable para el funcionamiento del órgano parlamentario surgió, como se ha dicho, en Inglaterra y se consolidó de manera paulatina por medio de costumbres y convenciones, hasta su culminación en la ley aprobada por el parlamento intitulada Ministers of the Crown Act de 1937, que con otros ordenamientos posteriores estableció una regulación sobre la oposición considerada como una institución pública, ya que el jefe del partido que no obtuvo la mayoría en las elecciones en un régimen esencialmente bipartidista, es considerado como funcionario público, y puede designar a sus colaboradores, con lo que se conforma lo que se considera como Shadow Cabinet, cuyos integrantes reciben una remuneración del erario público, ya que existe la alternativa de que puedan formar un nuevo gobierno en el caso de obtener la mayoría de votos en los siguientes comicios. ${ }^{20}$

19. Tratándose de regímenes parlamentarios bipartidistas, varios países de cultura británica y miembros de la Commonwealth, adoptaron instituciones similares a las inglesas, es decir establecieron un cargo público remunerado para el jefe de la oposición y sus colaboradores, similar al "Gabinete en la sombra", y en esta dirección podemos citar a Australia, Canadá y Nueva Zelandia. Aun cuando la Ley Fundamental de la República Federal de Alemania no contiene una disposición similar, no obstante ser un régimen parlamentario predominantemente bipartidista, sí se ha establecido regulación semejante a los de los países de la Commonwealth mencionados anteriormente, en las Constituciones de dos Estados alemanes, como son las de Baden de 22 de mayo de 1947 , artículo $120^{\circ}$ y de Hamburgo de 1946 , artículo $25^{\circ}$ reformado en 1971 , así como la ley de Schlessig-Holstein de 1955, ordenamientos que establecieron el Füher der Opposition. ${ }^{21}$

$19 \mathrm{Voz}$ “Opposizione parlamentare», op. cit. supra nota 4, pp. 536-539.

20 Cfr. Giuseppe de Vergottini, Lo "Shadow Cabinet" (Saggio comparativo sul rilievo costituzionale della oppsiziore nel regimen parlamentare britannico), Milán, Giuffrè, 1973, possim.

21 Cfr. Giuseppe de Vergotrini, Diritto Costituzionale Comparato, cit. supra nota 4, pp. 406-408; Juan Fernando López Aguilar, Minoria y oposición en el parlamentarismo, cit. supra nota 5, pp. 210-212. 
20. Debe mencionarse también el artículo $117^{\circ}$, inciso 2 , de la Constitución Portuguesa (1976-1982), el cual dispone: «Se reconoce a las minorías el derecho de oposición democrática en los términos de la Constitución». Dicho precepto fue reglamentado por la Ley $\mathrm{N}^{\circ} 59$ de 1977, que regula en especial las facultades extralegislativas que hasta entonces estaban reservados a los grupos parlamentarios por los artículos constitucionales $179^{\circ}$, inciso $3 ; 183^{\circ}$, inciso $2 ; 195^{\circ}$, inciso $3 ; y 197^{\circ}$, inciso $2 ; 195^{\circ}$, inciso $3 ;$ y $197^{\circ}$, inciso 2 , sobre los diversos derechos que se otorgan a los varios grupos legislativos. Dicha ley de 1977 define la oposición democrática como "toda actividad democrática de crítica y fiscalización política de la acción del Gobierno y la formulación de alternativas constitucionalmente legítimas al Gobierno. El propio ordenamiento confiere a los partidos de oposición, entre otros, los derechos de información, de participación, de consulta y de acceso a los medios de comunicación social. Además la citada ley reconoce el derecho de oposición a los partidos políticos representados en las asambleas regionales y que no formen parte del respectivo gobierno. ${ }^{22}$

21. Por lo que respecta al ordenamiento español, si bien no existe un precepto constitucional que reconozca expresamente la función de la oposición, se advierte la decisión de las Cortes de conformar un Estatuto formal de Oposición, en la combinación de un conjunto de resoluciones interpretativas y supletorias del Reglamento Interno del Congreso, con base en las cuales se suscribió un Acuerdo de la Mesa del Congreso de los Diputados el 8 de febrero de 1983, de conformidad con el cual se reconoció la figura parlamentaria del «Jefe de la Oposición" en tanto que presidente del Grupo Parlamentario mayoritario de cuantos componen la misma, figura que se incorporó al Real Decreto del 4 de agosto del mismo año de 1983, que regula el Protocolo y Precedencias Oficiales del Estado, en el cual aparece el Jefe de la Oposición con el número 15 en el elenco de la prelación institucional de autoridades del Estado.

22. Por lo que respecta a los ordenamientos constitucionales de América Latina, debemos hacer especial referencia a los artículos $112^{\circ}$ de la Constitución colombiana de 1991, y $117^{\circ}$ de la Carta Fundamental de Ecuador, reformada en 1998. El primer precepto tiene el epígrafe de Estatuto de Oposición y lo siguiente:

22 Cfr. J.J. Gomes Canotilho y Vital Moreira, Constituiçâo da Repuiblica Portuguesa, Anotada, Coimbra, Coimbra Editora, 1980, pp. 270-271. 
«Los partidos y movimientos políticos que no participen en el Gobierno, podrán ejercer libremente la función crítica frente a éste y plantear y desarrollar alternativas políticas. Para estos efectos, salvo las restricciones legales, se les garantizan los siguientes derechos: de acceso a la información y a la documentación oficiales; de uso de los medios de comunicación del Estado de acuerdo con la representación obtenida en las elecciones para el Congreso inmediatamente anteriores; de réplica en los medios de comunicación del Estado frente a tergiversaciones graves o evidentes o ataques públicos proferidos por altos funcionarios oficiales, y de participación en los organismos electorales. Los partidos y movimientos minoritarios tendrán derecho a participar en las mesas directivas de los cuerpos colegiados, según su representación en ellos. Una ley estatutaria regulará íntegramente la materia.»

A su vez el mencionado artículo $117^{\circ}$ de la Ley Fundamental ecuatoriana, que al parecer se inspiró parcialmente en el precepto anterior del ordenamiento constitucional colombiano, establece de manera menos extensa:

«Los partidos y movimientos políticos que no participen del gobierno, tendrán plenas garantías para ejercer, dentro de la Constitución y la ley, una oposición crítica, y proponer alternativas sobre políticas gubernamentales. La ley regulará este derecho.»

\section{La constitucionalización de los partidos políticos en México}

23. El texto original de la Constitución Federal mexicana de 5 de febrero de 1917 no contenía una regulación de los partidos políticos, debido a que fue expedida en una época en la que todavía no se iniciaba la tendencia hacia la constitucionalización de dichos partidos, que como se dijo anteriormente, comenzó en la segunda postguerra (ver supra párrafo 6). Por tanto, la organización y funciones de los propios partidos se regulaba en las leyes electorales, tanto en el ámbito Federal como en el de las Entidades Federativas. ${ }^{23}$

23 Cfr. Legislación Electoral Mexicana, 1812-1973, México, Secretaría de Gobernación, Diario Oficial, 1973 
24. Por otra parte, la realidad política no favoreció a los grupos políticos minoritarios debido a la creación en el año de 1929 del entonces Partido Nacional Revolucionario (PRN), que en 1938 se transformó en Partido de la Revolución Mexicana (PRM) y que finalmente se convirtió en 1946 en el actual Partido Revolucionario Institucional (PRI), que por casi siete décadas funcionó como un partido hegemónico, considerado como un caso excepcional dentro de la inestabilidad política latinoamericana, el cual acaparó prácticamente todos los cargos de elección popular, desde los municipales, hasta los Gobiernos Estatales y el de carácter federal, todo ello con apoyo en un sistema electoral de mayoría relativa y unos sufragios de dudosa legitimidad. ${ }^{24}$ Sin embargo dicho Partido no podía considerarse, como algunos autores lo califican, de "Partido Único", ya que al menos formalmente admitía la existencia de otras agrupaciones políticas, aun cuando sin la posibilidad real de alternancia en el poder, por lo que esta etapa correspondió a la considerada «límite» en el concepto de Vergottini (ver supra párrafo 17).

25. En el año de 1963 se intentó una reforma constitucional bastante tibia para favorecer a los débiles partidos de oposición, al modificar el sistema mayoritario integral para introducir en el artículo $54^{\circ}$ de la Carta Federal, un principio de representación proporcional bastante restringido, por medio de los llamados diputados de partido, que podían obtener los partidos políticos nacionales que hubiesen conseguido el dos y medio por ciento de la votación total en el país, en un número de cinco diputados, y uno más, hasta veinte, por cada medio por ciento más de los votos emitidos. Este porcentaje resultó excesivo debido a la escasa representatividad de algunos de dichos partidos, por lo que se redujo al uno $y$ medio por ciento en la reforma al citado precepto fundamental en el año de 1972. Con tales modificaciones el PRI, que obtenía anteriormente más del noventa por ciento de los votos de mayoría, los redujo al $82.28 \%$, y la oposición llegó al $17.22 \%$, ya que en la legislatura electa en 1976, último año de este sistema, la Cámara de Diputados se integró con 237 curules, de las cuales el partido hegemónico obtuvo 195 y la oposición $41 .^{25}$

24 Cfr. Alejandra Lajous, Los origenes del partido ínico en México, México, UNAM, 1979; Luis Javier Garrido, El partido de la revolución institucionalizada. La formación del nuevo Estado en México (1929-1945). México, Secretaría de Educación Pública, 1986.

25 Cfr. Javier Patiño Camarena, Derecho electoral mexicano, México, UNAM, 1994, pp. 208-209; Francisco J. de Andrea Sánchez, “Evolución de las instituciones electora- 
26. El inicio de una verdadera reforma electoral se puede situar en la modificación constitucional a varios preceptos fundamentales en el mes de diciembre de 1977, promovida por el entonces Secretario de Gobernación, el destacado jurista y político mexicano Jesús Reyes Heroles. Entre los cambios esenciales introducidos deben mencionarse, en primer término la constitucionalización de los partidos políticos de acuerdo con la tendencia que se ha señalado con anterioridad (ver supra párrafos 5 y 6), y el establecimiento de un régimen mixto de mayoría con distritos uninominales y un verdadero sistema de representación proporcional por medio de distritos plurinominales, lo que permitió, a partir de entonces, el fortalecimiento de varios partidos políticos nacionales, inclusive algunos radicales de izquierda, como el partido comunista, de derecha como el tradicional sinarquista, que obtuvieron su registro condicionado, y posteriormente se fusionaron con otros. ${ }^{26}$

27. Por lo que respecta al reconocimiento de la función constitucional de los partidos políticos, calificados como instituciones de interés público el texto reformado del artículo $41^{\circ}$ de la Carta Federal, dispuso:

«Los partidos políticos son entidades de interés público, la ley determinará las formas específicas de su intervención en el proceso electoral. Los partidos políticos tienen como fin promover la participación del pueblo en la vida democrática, contribuir a la integración de la representación nacional y como organizaciones de ciudadanos, hacer posible el acceso de éstos al ejercicio del poder público, de acuerdo con los programas, principios e ideas que postulan y mediante el sufragio universal, libre, secreto y directo. Los partidos políticos tendrán derecho al uso en forma permanente de los medios de comunicación social, de acuerdo con las formas y procedimientos que establezca la ley. En los procesos electorales federales, los partidos políticos nacionales deberán contar, en forma equitativa, con un mínimo de elementos para sus actividades tendientes a la obtención del sufragio popular. Los partidos políticos nacionales tendrán derecho a participar en las elecciones estatales y municipales.»

les mexicanas: época contemporánea", en La renovación politica y el sistema electoral mexicano, México, Porrúa, 1987, pp. 99-105.

26 Cfr. entre otros, La reforma politica y los partidos en México, editado por Octavio Rodríguez Araujo, México, Siglo XXI, 1979. 
28. Se debe destacar que en esta reforma de diciembre de 1977, se establecieron dos instrumentos para fortalecer a los partidos políticos de oposición, como son los relativos al uso permanente de los medios de comunicación social, y al financiamiento público de sus actividades tendientes a la obtención del sufragio, que debía ser desde entonces, de carácter equitativo, e inclusive se estableció un sistema incipiente de resolución de controversias electorales de carácter judicial, ya que se introdujo un recurso de reclamación ante la Suprema Corte de Justicia contra las decisiones finales de los órganos administrativos electorales, que careció de resultados prácticos, debido a su carácter excesivamente formal. ${ }^{27}$ Estas modificaciones constitucionales fueron desarrolladas por la Ley Federal de Organizaciones Políticas y Procesos Electorales de 30 de diciembre de 1977.

29. A partir de la mencionada reforma sustancial de diciembre de 1977, se avanzó de manera paulatina en la consolidación del incipiente pluralismo implantado entonces, y se realizaron otras reformas constitucionales importantes, todas de carácter progresivo en cuanto a los derechos de los partidos políticos y su participación en los organismos electorales de carácter administrativo, así como la tendencia hacia la creación de organismos jurisdiccionales en esta materia. En efecto, en el año de 1986 se creó el Tribunal de lo Contencioso Electoral que se integraba únicamente en los períodos electorales, y con facultades decisorias todavía limitadas y se componía con siete magistrados numerarios y dos supernumerarios nombrados por el Congreso de la Unión a propuesta de los partidos políticos. ${ }^{28}$

30. Un paso adelante significaron las reformas constitucionales de 1990, ya que sustituyeron el anterior Tribunal de lo Contencioso Electoral, por el Tribunal Federal Electoral de carácter permanente. Este último poseía plena autonomía para dictar sus fallos y sus magistrados no tenían carácter partidista, puesto que eran designados a propuesta del presidente de la República y aprobados por el Congreso de la Unión. Estaba integrado por una Sala Central que funcionaba de manera continua en la ciudad de México y durante el período de elecciones se forma-

27 Cfr. Jorge Carpizo, "La reforma política mexicana de 1977", en su libro Estudios constitucionales, 5. Ed., México, Porrúa-UNAM, 1996, pp. 351-405.

28 Cfr. Enrique Sánchez Bringas, "Contencioso electoral", en el libro La renowación política y el sistema electoral mexicano, cit. supra nota 25, pp. 243-249. 
ban cuatro salas regionales. Sin embargo las decisiones finales de este organismo jurisdiccional electoral no tenían carácter definitivo ya que podían ser revisadas en ciertos supuestos por las Cámaras federales, que pronunciaban el fallo final (artículos $41^{\circ}$ y $60^{\circ}$ de la Carta Fundamental, reglamentados por el Código Federal de Instituciones y Procedimientos Electorales del mismo año de 1990). ${ }^{29}$

31. El desarrollo hacia la jurisdicción electoral continuó en el ordenamiento mexicano por medio de la reforma constitucional publicada el 3 de septiembre de 1993, que suprimió el sistema de autocalificación definitiva para las Cámaras de Diputados y Senadores del Congreso de la Unión, que se atribuyó al citado Tribunal Federal Electoral y sólo se conservó la decisión final sobre la elección del Presidente de la República por parte de la Cámara de Diputados (artículo $74^{\circ}$, fracción I, de la Constitución Federal).

32. De acuerdo con las disposiciones de la citada reforma de 1993, el Tribunal Federal Electoral era el órgano autónomo y máxima autoridad jurisdiccional electoral. Se integraba en pleno y en salas regionales, que resolvían en forma definitiva las impugnaciones que se presentaran en materia electoral federal (con exclusión de la relativa al presidente de la República, según se expresó en el párrafo anterior). Las resoluciones de las salas podían ser revisadas por una sala de segunda instancia integrada por cuatro miembros de la judicatura federal, designados por el voto de las dos terceras partes de los miembros de la Cámara de Diputados entre los propuestos por la Suprema Corte de justicia. Dicha sala era encabezada por el presidente del citado Tribunal Federal Electoral (artículos $41^{\circ}$ y $60^{\circ}$ de la Carta Federal). Como puede observarse se produjo una transformación muy significativa respecto a la solución de los conflictos electorales, que se confiaron a un tribunal especializado por medio de un verdadero proceso contencioso electoral, y que decidía de manera definitiva y firme dichos conflictos. ${ }^{30}$

33. Esta evolución de las instituciones político-electorales ha culminado con la reforma constitucional de 23 de agosto de 1996. La innova-

29 Cfr. Arturo Núñez Jiménez, El nuevo sistema electoral mexicano, Mćxico, FCE, 1991, pp. 239-311.

30 Cfr. Javier Patin̄o Camarena, Derecho Electoral Mexicano, cit, supra nota 25, pp. 497-527; con respecto del funcionamiento de dicho tribunal en la resolución de conflictos derivados de las elecciones federales de 1994, legislativas y presidenciales, puede consultarse la Memoria, 2 vols., México, Tribunal Federal Electoral, 1995. 
ción de mayor trascendencia según mi punto de vista, consiste en la incorporación del Tribunal Federal Electoral al Poder Judicial de la Federación. Este nuevo tribunal considerado por el texto actual del artículo $99^{\circ}$ constitucional (con excepción de lo dispuesto en la fracción II del artículo $105^{\circ}$ constitucional, o sea la impugnación ante la Suprema Corte de Justicia de las leyes electorales por las dirigencias de los partidos políticos por medio de la acción de inconstitucionalidad, ver infra párrafo 58), como la "máxima autoridad jurisdiccional en la materia y órgano especializado del Poder Judicial de la Federación». De acuerdo con lo anterior, la estructura y funciones de este organismo jurisdiccional especializado están reglamentadas actualmente por el título undécimo de la Ley Orgánica del Poder Judicial de la Federación (artículos $184^{\circ}-241^{\circ}$ ), en los términos de las reformas a dicha ley publicadas el 22 de noviembre de 1996.

34. El mencionado Tribunal Electoral del Poder Judicial de la Federación está integrado por una sala superior y por salas regionales, de carácter permanente, cuyos magistrados son elegidos por el voto de las dos terceras partes de los miembros presentes de la Cámara de Senadores a propuesta de la Suprema Corte de Justicia. Entre sus funciones más importantes está la de decidir de manera firme sobre las impugnaciones en las elecciones de los diputados y senadores federales, así como las que se presenten sobre la elección del presidente de la República (en este último supuesto, en última instancia). ${ }^{31}$

35. Por vez primera en el sistema constitucional mexicano se atribuye a la sala superior del Tribunal Electoral del Poder Judicial de la Federación el cómputo final de la elección del presidente de la República, una vez resueltas, en su caso, las impugnaciones que se hubieran interpuesto con lo que procede dicho Tribunal a formular la declaración de validez de los sufragios y la del presidente electo respecto del candidato que hubiese obtenido el mayor número de votos. En la actualidad corresponde a la Cámara de Diputados únicamente expedir el bando solemne para dar a conocer en toda la República la declaración de presidente electo que hubiere hecho el citado Tribunal Electoral (artículo $74^{\circ}$, fracción IV de la Carta Federal). ${ }^{32}$ Ha sido significativo el desarro-

31 Cfr. Flavio Galván Rivera, Derecho procesal electoral mexicano, cit. supra nota 14, pp. 79-130.

32 Cfr. Héctor Fix-Zamudio, «¿Constitución renovada o nueva Constitución?»; en 80 Aniversario. Homenaje a la Constitución Politica de los Estados Unidos Mexicanos, 
llo de los procedimientos jurisdiccionales, y por ello las normas adjetivas se independizaron de las sustantivas y se concentraron en un ordenamiento específico denominado Ley General del Sistema de Medios de Impugnación en Materia Electoral, publicado el 22 de noviembre de $1996 .^{33}$

36. También se debe subrayar que en las mencionadas reformas constitucionales y legales de 1996, se reformó sustancialmente la integración y funcionamiento del organismo administrativo encargado de organizar las elecciones federales y la actividad permanente de los partidos y agrupaciones políticas, es decir la anterior y tradicional Comisión Federal Electoral que se transformó en el Instituto Federal Electoral en las modificaciones constitucionales de 1990, hasta antes de la citada reforma de 1996, el Consejo General del citado instituto estaba encabezado por el Secretario de Gobernación y los integrantes del propio Consejo se cambiaron de manera paulatina, pero siempre con intervención activa de los representantes de los partidos políticos, es decir, con voz y voto. El referido Consejo General de dicho instituto se integró a partir de octubre de 1990 a abril de 1994 con cinco consejeros representantes del Estado (el representante del Ejecutivo era citado Secretario de Gobernación) con seis consejeros magistrados representantes de la sociedad con voz y voto, y con representantes de los partidos políticos nacionales cuyo número y votos podían oscilar entre uno y cuatro, según la votación nacional obtenida por cada uno de ellos en la anterior elección de diputados de mayoría relativa. En la reforma constitucional de marzo de 1994, se modificó la integración del citado Consejo General que se conformaba con un consejero del poder ejecutivo (Secretario de Gobernación), con cuatro consejeros del poder legislativo, con seis consejeros, ya no denominados magistrados, sino ciudadanos, todo los cuales tenían voz y voto y con sendos representantes de los partidos políticos nacionales, con voz pero sin voto. ${ }^{34}$

México, Comisión Plural Organizadora del LXXX Aniversario de la Constitución Política de los Estados Unidos Mexicanos - Senado de la República - UNAM, 1997, pp. 108-109.

33 Cfr. Edmundo Elías Musi (coord.), Estudio teórico-práctico del sistema de medios de impugnación en materia electoral, México, Centro de Capacitación Judicial Electoral del Tribunal Electoral del Poder Judicial de la Federación, 1997.

34 Cfr. Javier Patiño Camarena, Derecho Electoral Mexicano, cit. supra nota 25, pp. 366-376. 
37. Sin embargo la mencionada reforma constitucional de 22 de agosto de 1996, y las modificaciones al Código Federal de Instituciones Políticas y Procedimientos Electorales de 31 de octubre de ese año, como resultado de intensas negociaciones del ejecutivo federal con los partidos políticos, significó un cambio importante dirigido hacia la mayor autonomía e independencia al citado Instituto Federal Electoral, ${ }^{35}$ ya que a partir de entonces se excluye totalmente al Poder Ejecutivo Federal de su Consejo General, el cual se integra por un Presidente y ocho consejeros electorales con el mismo número de suplentes (todos ellos calificados como "ciudadanos» a partir de las reformas de 1994, que iniciaron lo que se ha denominado «ciudanización de los órganos administrativos electorales") y que son elegidos sucesivamente, por el voto de las dos terceras partes de los miembros presentes de la Cámara de Diputados, o en sus recesos, por la Comisión Permanente a proposición de los grupos parlamentarios y por un período de siete años. Acudirán al Consejo con voz pero sin voto, los consejeros del poder legislativo (uno por cada grupo parlamentario); los representantes de los partidos políticos y un secretario ejecutivo. Por este motivo, los únicos que pueden tomar decisiones son los nueve consejeros ciudadanos, que no representan a partido político alguno, sino que se pretende lo sean de la sociedad civil en su conjunto.

38. Con las citadas modificaciones se tiene el propósito de que no intervenga el ejecutivo federal en la organización y los procedimientos electorales, y que los representantes del poder legislativo y de los partidos políticos sólo tenga voz pero no voto en el Consejo General de dicho Instituto, por lo que este último es calificado como «Organismo público autónomo", por el texto actual del artículo $41^{\circ}$ de la Carta Federal, el cual también agregó que el propio Instituto es independiente

35 En la parte relativa de la base III del artículo $41^{\circ}$ constitucional, en su texto reformado en 1996 se dispone que: "La organización de las elecciones federales es una función estatal que se realiza a través de un organismo público autónomo denominado Instituto Federal Electoral, dotado de personalidad jurídica y patrimonio propios, en cuya integración participa el Poder Legislativo de la Unión, los partidos políticos nacionales y los ciudadanos en los términos que ordene la ley. En el ejercicio de esa función estatal, la certeza, legalidad, independencia, imparcialidad y objetividad serán principios rectores. El instituto Federal Electoral será autoridad en la materia, independiente en sus decisiones y funcionamiento y profesional en sus desempeño; [... ." 
en sus decisiones y en su funcionamiento, todo ello para garantizar el carácter imparcial de las elecciones federales. ${ }^{36}$

\section{El Estatuto de la oposición}

39. Aun cuando la Constitución Federal mexicana no consagra disposiciones específicas, como las que se han mencionado con anterioridad respecto de Inglaterra y otros países de la Commonwealth, algunas cartas de los Estados de la República Federal de Alemania, Portugal así como Colombia y Ecuador en Latinoamérica, sin embargo contienen varias disposiciones, tanto de carácter constitucional como legislativas, que establecen instrumentos que fortalecen a los partidos y organizaciones políticas que no se encuentran en el Gobierno. Estas instituciones se han desarrollado con rapidez a partir de la mencionada reforma constitucional de diciembre de 1977 (ver supra párrafos 26-29), ya que se avanzó con rapidez en las modificaciones sucesivas de 1987, 1990, 1993, y 1994 y finalmente las más recientes de 1996, que permitieron la consolidación y creciente fortaleza de los partidos de oposición que incrementaron su participación tanto en las elecciones federales, como en las estatales y las municipales.

40. A partir de la existencia de un partido hegemónico, las sucesivas reformas constitucionales y legales de carácter electoral, una vez reconocida la función constitucional de los partidos políticos en 1977 (ver supra párrafo 27), favorecieron a los partidos de oposición y si bien hasta las elecciones presidenciales de 1994, el Jefe del Ejecutivo Federal ha pertenecido de manera invariable al Partido Revolucionario Institucional, el que todavía obtuvo la mayoría absoluta en ambas Cámaras en dichas elecciones federales, esta situación ha cambiado con posterioridad y en las elecciones legislativas de 1997 dicho partido perdió dicha mayoría en la Cámara de Diputados, lo que debe considerarse como un acontecimiento excepcional. Por otra parte, los partidos de oposición han incrementado su acceso a los gobiernos de varias entidades federativas, así como en las legislaturas locales y en los municipios, todos con integración pluralista.

36 Cfr. Eduardo Andrade Sánchez, La reforma politica de 1996 en México, México, Cuadernos Constitucionales México-Centroamérica, 25, UNAM, 1997, pp. 87 107. 
41. Además, se modificó sustancialmente también en agosto de 1996 el artículo $122^{\circ}$ constitucional, con una redacción excesivamente extensa, para ampliar las facultades legislativas de la Asamblea Legislativa (antes de Representantes) del Distrito Federal, y además establecer el cargo de Jefe del Gobierno del Distrito Federal (anteriormente libremente designado y removido por el Presidente de la República) electo por sufragio universal, libre, directo y secreto por los ciudadanos del propio Distrito Federal. ${ }^{37}$ En las elecciones de 1997 fue electo como jefe del Gobierno del propio Distrito Federal el ingeniero Cauhtémoc Cárdenas, del Partido de la Revolución Democrática, el cual obtuvo también la mayoría absoluta en la referida Asamblea Legislativa.

42. De manera sintética se pueden señalar las disposiciones tanto constitucionales como legislativas que establecen derechos e instituciones que pueden ser considerados en su conjunto, como un estatuto de la oposición en el ordenamiento mexicano. a) En primer término podemos señalar el derecho de los partidos políticos para acceder a los medios de comunicación social (ver supra párrafo 26), lo que les ha permitido dar a conocer sus programas y sus proyectos de alternativa política.

43. b) Los partidos reciben financiamiento público para sus gastos de campaña electoral, todo ello de acuerdo con el resultado de las últimas elecciones, que es el sistema que generalmente se sigue en la mayoría de las legislaciones electorales. ${ }^{38}$ De acuerdo con la doctrina, son tres los objetivos centrales de la financiación de los partidos políticos en México: dar plena supremacía al financiamiento público sobre el financiamiento privado; equilibrar la competencia, es decir, propiciar condiciones de mayor equidad en las campañas y finalmente, posibilitar un examen más incisivo y profundo de las estructuras contables, para hacer más transparentes las finanzas de los partidos. En tal virtud, el $30 \%$ de la cantidad total se distribuye entre los partidos en forma igualitaria y el $70 \%$ restante se reparte entre los mismos de acuerdo con el porcentaje de votos que hubiere obtenido en la elección de diputados federales inmediata anterior (que se realiza cada tres años). ${ }^{39}$

37 Cfr. Eduardo Andrade Sánchez, op. ult. cit. pp. 237-262.

38 Cfr. Daniel Zovatto G., "La financiación política en Iberoamérica. Una visión preliminar comparada", en la obra La financiación de la política en Iberoamérica, cit. supra nota 10) pp. XI-CX.

39 Cfr. José Woldenberg, Ricardo Becerra y Pedro Salazar, «El modelo de financiación de los partidos políticos en México", en el libro citado en la nota anterior pp. 321- 
44. c) El sistema electoral de carácter mixto, de mayoría y de representación proporcional establecido en la reforma constitucional de diciembre de 1977 (ver supra párrafo 26), que se perfeccionó de manera paulatina, de tal manera que en la citada reforma constitucional al artículo $53^{\circ}$ constitucional se establecieron trescientos distritos uninominales de mayoría y cinco circunscripciones territoriales plurinominales, para la elección de cien diputados de representación proporcional. Estos últimos se elevaron a doscientos en las modificaciones constitucionales de 1986, que es la regulación que se conserva hasta la actualidad, es decir, de quinientos miembros de la Cámara de Diputados, de los cuales trescientos se eligen por mayoría en distritos electorales uninominales y doscientos de representación proporcional en cinco distritos plurinominales.

45. El régimen mixto ha permitido, también de manera paulatina el fortalecimiento de los partidos de oposición, que han incrementado su membrecía en la Cámara de Diputados, de tal manera que en la última elección para integrar la Cámara de Diputados en junio de 1997, el Partido Revolucionario Institucional (PR), perdió la mayoría absoluta que había obtenido desde su fundación, pues sólo tiene actualmente 239 diputados federales, es decir $47.8 \%$ de la votación total; en tanto que los partidos que no se encuentran en el Gobierno, tienen en su conjunto la mayoría de las curules: el Partido de Acción Nacional (PAN) 122 menos uno que se declaró independiente (121), (24.2\%); el Partido de la Revolución Democrática (PRD), 125, más uno que se le adhirió (126), (25.2\%); el Partido del Trabajo, 6, (1.2\%), y el Partido Verde Ecologista Mexicano (PVEM), 8, menos dos que se declararon independientes de los sufragios (6), más los independientes, en total 500. Además, han surgido otras agrupaciones políticas que aspiran al registro, como el Partido del Centro Democrático y el Partido Demócrata Social Mexicano, entre otros, lo que indica claramente los resultados favorables para la oposición de la aplicación del sistema mixto electoral que hemos señalado.

46. Por lo que respecta a la Cámara de Senadores, se mantuvo por más tiempo con apoyo en el sistema de mayoría, con el argumento de que sus integrantes representaban a los Estados de acuerdo con el régi- 
men federal, razonamiento inconsistente en cuanto son designados por voto directo y universal. Por tal motivo se impuso con cierta dificultad el sistema mixto, aun cuando modificado por lo que respecta a la integración de dicha Cámara que actualmente se forma por 4 senadores federales por cada Estado y por el Distrito Federal, de los cuales 2 son electos por el sistema de mayoría, otro por el de primera mayoría y el cuarto según el régimen de representación proporcional, por lo que se llega a un total de 128 senadores. El Partido Revolucionario Institucional conserva la mayoría en el propio Senado, ya que obtuvo 77 senadores (60.1\%), en tanto que el Partido de Acción Nacional 33 (25.8\%); el Partido de la Revolución Democrática 15 (11.7\%); el Partido del Trabajo, 1 (0.8\%); el Partido Verde Ecologista Mexicano 1 y un independiente, en la última elección para el Senado Federal ( 6 de julio de 1994), que se renueva cada 6 años, y que coincide con los sufragios para la presidencia de la República. ${ }^{40}$

47. d) La existencia de un registro electoral confiable. Debido al sistema de partido hegemónico que imperó por varias décadas en nuestro país, el registro electoral adolecía de defectos graves que no lo hacían de ninguna manera adecuado para servir de apoyo a las transformaciones hacia el pluripartidismo que actualmente predomina en el actual régimen federal. Pero en el breve período en el cual presidió el Consejo General del Instituto Federal Electoral (1993-1994), el entonces Secretario de Gobernación, el Dr. Jorge Carpizo, se hizo un esfuerzo considerable para lograr un registro electoral con todos los adelantos técnicos, y por este motivo las elecciones federales de 1994 para elección de diputados, senadores y Presidente de la República, se realizaron con apoyo en un registro electoral muy confiable, como lo reconocieron los partidos políticos contendientes. Es indudable que un registro electoral adecuado también se traduce en una garantía para la oposición política, como los resultados a partir de entonces lo demuestran con claridad en México. ${ }^{41}$

40 Cfr. Susana Thalía Pedroza de la Llave, "Poderes legislativo y ejecutivo», en la obra Transacciones y diseños institucionales, editado por María del Refugio González y Sergio López Ayllón, México, UNAM, 1999, pp. 163-164.

41 Cfr. Juan Manual Herrero, "Diagnóstico del registro electoral en México", en Registro Civil y Electoral en Iberoamérica, San José de Costa Rica, Instituto Interamericano de Derechos Humanos - Capel, 1977, pp. 589-503; Marta León Rosch, "Los registros electorales", en Tratado de Derecho Electoral Comparado de América Latina, cit. supra nota 7 , pp. 250-307. 
48. e) Participación de los grupos parlamentarios de oposición en las comisiones legislativas. El texto actual del artículo $70^{\circ}$ de la Carta Federal en su párrafo segundo dispone que la ley determinará las formas y procedimientos "para la agrupación de los diputados según su afiliación de partido, a efecto de garantizar la libre expresión de las corrientes ideológicas representadas en la Cámara de Diputados». Este precepto ha sido desarrollado por la ley Orgánica del Congreso General, en vigor a partir del 25 de mayo de 1979, pero reformada sustancialmente en 1994, que otorga una gran importancia a los grupos parlamentarios en las actividades de la citada Cámara de Diputados, tanto para la integración de la mesa directiva, como en la formación de las Comisiones permanentes y especiales.

49. Debe destacarse la introducción de la Comisión de Régimen Interno y de Concertación Política, que se integra con los coordinadores de cada uno de los diversos grupos parlamentarios partidistas, más otros tantos del grupo mayoritario de la Cámara. Funciona como órgano de gobierno a fin de optimizar el ejercicio de las funciones legislativas, políticas y administrativas que tiene la propia Cámara, y entre sus funciones posee la de proponer a los integrantes de las Comisiones y Comités (artículo $45^{\circ}$ de la Ley). Las Comisiones se integran por no más de treinta diputados electos por el Pleno de la Cámara a propuesta de la citada Comisión de Régimen Interno y de Concertación Política, cuidando que en ella se encuentren representados los diferentes grupos parlamentarios, tanto en las presidencias como en las secretarías correspondientes y a este efecto debe tomarse en cuenta la importancia cuantitativa de cada grupo parlamentario, con la participación de los diferentes grupos parlamentarios, tanto en las presidencias como en las secretarías correspondiente. A este efecto se tomará en cuenta la importancia cuantitativa de cada grupo parlamentario, (artículo $47^{\circ}$ ).

50. En la Cámara de Senadores existe un régimen similar ya que el artículo $94^{\circ}$ de la Ley Orgánica del Congreso invoca el artículo $70^{\circ}$ constitucional (que como se ha dicho, se refiere a la Cámara de Diputados), para constituir los grupos parlamentarios de los senadores con el objeto de realizar las tareas especificas de la Cámara y coadyuvar al mejor desarrollo del proceso legislativo. Como órgano de gobierno actúa la Gran Comisión, que se integra con un senador de cada Estado y del Distrito Federal y así como con los coordinadores de los grupos parla- 
mentarios, órgano que tiene entre sus funciones proponer el personal de las comisiones ordinarias y especiales (artículos $\left.91^{\circ}-93^{\circ}\right) .^{42}$

51. Se pueden encontrar otros instrumentos que es posible integrar al estatuto de la oposición en México, aun cuando no estén establecidas sólo con este propósito como lo señalamos anteriormente, en cuanto al establecimiento y perfeccionamiento paulatino del actual tribunal Electoral del Poder Judicial Federal (ver supra párrafos 29-35), y la transformación del órgano administrativo encargado de organizar las elecciones federales, que constituye en nuestros días un organismo autónomo e independiente de los restantes poderes públicos. Estos mecanismos se han establecido también en los ordenamientos de los diversos Estados y del Distrito Federal, por lo que las elecciones de carácter local, han permitido a los partidos de oposición obtener importante participación en los cargos de representación popular, así como la titularidad del ejecutivo, legislaturas y municipios en varias de esas entidades federativas. Se puede destacar que en la actualidad, de las 33 entidades federativas, el Partido de Acción Nacional tiene la titularidad del Gobierno en los Estados de Aguascalientes, Baja California, Guanajuato, Jalisco, Nuevo León y Querétaro, en tanto que el Partido de la Revolución Democrática de la Baja California Sur, Distrito Federal, Tlaxcala y Zacatecas. En las restantes, todavía predomina el Partido Revolucionario Institucional, lo que significa un gran avance para los partidos de oposición si se toma en cuenta que hasta hace algunos años abarcaba todas las entidades federativas del país.

52. Un aspecto importante que falta en la legislación mexicana es la exigencia respecto a la democracia interna de los partidos políticos, no sólo respecto del PRI sino también en cuanto a los de la oposición, puesto que, hasta muy recientemente habían imperado las decisiones de la partitocracia. Así lo ha señalado agudamente el destacado constitucionalista mexicano Diego Valadés Ríos ("Una Democracia sin excepciones») en Excélsior (29 de marzo de 1999). Sin embargo se observa una evolución favorable en esta dirección en cuanto en la práctica, los mismos partidos políticos han organizado elecciones primarias, (que no se realizaban anteriormente, ya que las decisiones eran verticales), para designar candidatos a las elecciones locales efectuadas recientemente,

42 Cfr. Susana Thalía Pedroza de la Llave, El Congreso de la Unión. Integración y regulación, México, UNAM, 1997, pp. 141-191. 
y por lo que deben fijarse reglas para dichas elecciones primarias en vista a los sufragios presidenciales de diputados y senadores federales para el año 2000 .

\section{La acción abstracta de inconstitucionalidad y el juicio de revisión constitucional como garantías de la oposición}

53. Aun cuando otros instrumentos que se han señalado con anterioridad se han traducido directa o indirectamente en garantías para la oposición política en México, los dos procedimientos jurisdiccionales que ahora pretendo analizar muy brevemente, se han establecido con el objeto de permitir a los grupos y partidos políticos que no se encuentran en el gobierno, impugnar las disposiciones legislativas aprobadas por la mayoría en los órganos legislativos o combatir los resultados de una elección local cuando los afectados consideren que los organismos respectivos han infringido las normas de la Carta Federal.

54. a) La acción abstracta de inconstitucionalidad. Esta garantía constitucional fue introducida por vez primera en el ordenamiento constitucional mexicano con las reformas publicadas el 31 de diciembre de 1994, y de manera evidente se tomó del modelo europeo, en el cual surgió con el objeto de otorgar a las minorías parlamentarias la posibilidad de impugnar ante los organismos de justicia constitucional (cortes, tribunales constitucionales e inclusive el Consejo constitucional francés) las disposiciones legislativas aprobadas por la mayoría, especialmente en Austria, República Federal de Alemania, España, Francia y Portugal. ${ }^{43}$

55. Dicho instrumento constitucional debe considerarse como una acción de carácter "abstracto", es decir, que tiene por objeto esencial garantizar la aplicación de la Constitución y la certeza del orden jurídico fundamental, por lo que no se requiere la existencia de un agravio ni de un interés jurídico especifico para iniciar el procedimiento, y por ello generalmente se otorga la legitimación a los titulares de los poderes públicos (jefes de Estado o de gobierno), las Cámaras parlamentarias, los gobiernos centrales o las entidades federativas o de las comunidades autónomas, y en algunos supuestos también los organismos no jurisdic-

43 Cfr. Luca Mezzetri, Gitustizia costituzionale ed opposizione parlamentare. Modelli europei a confronto, Rimini, Maggiole Editore, 1992. 
cionales de protección de los derechos humanos creados de acuerdo con el modelo escandinavo del Ombudsman o inclusive por medio de acción popular. Además, dichas acciones abstractas pueden ser de carácter previo, o sea, pueden invocarse durante el procedimiento de discusión y aprobación, antes de la promulgación y publicación de la norma impugnada (como ocurre particularmente en Francia, en la instancia ante el Consejo Constitucional), ${ }^{44}$ o bien a posteriori, cuando las disposiciones legislativas ya han sido publicadas. Este último es el modelo que sigue el ordenamiento mexicano. ${ }^{45}$

56. En los ordenamientos de Europa Occidental en los cuales se ha establecido esta acción abstracta de inconstitucionalidad de las disposiciones legislativas en beneficio de un sector de los parlamentarios de la minoría, generalmente un $30 \%$ de los mismos, ha tenido un desarrollo bastante significativo y, además, ha logrado una fiscalización constante y frecuente de los ordenamientos aprobados por las mayorías legislativas, en forma destacada en la República Federal de Alemania, ${ }^{46}$ y en Francia. ${ }^{47}$ Esta acción abstracta de inconstitucionalidad escasamente conocida en el derecho constitucional latinoamericano, debe considerarse como un instrumento importante para otorgar garantías jurídicas a la oposición, según se ha dicho, a fin de que ésta pueda participar más activamente en las decisiones políticas de gobierno.

57. De acuerdo con lo establecido por la fracción II, incisos a) y e) de los artículos $105^{\circ}$ constitucional y $62^{\circ}$ de la Ley Reglamentaria de las fracciones I y II del citado precepto fundamental, publicada en febrero

44 Cfr., entre otros, François, Le Conseil Constitutionnel, París, Economica, 1980 , pp. $106-144$.

45 Cfr. Héctor Fix-Fierro, "La reforma judicial de 1994 y las acciones de inconstitucionalidad», en Ars Iuris, Revista del Instituto de Documentación e Investigación Jurídicas de la Facultad de Derecho de la Universidad Panamericana, Núm. 13, especial sobre la reforma judicial, 1995, pp. 114-117.

46 Cfr. Luca Mezzetti, Giustizia costituzionale e opposizione, cit. supra nota 44, p. 114. Este autor considera que la jurisprudencia constitucional alemana se ha originado de manera predominante debido a los impulsos que provienen de la oposición, pp. 62 69; Jean Claude Béguin, Le contrôle de la constitutionnalité des lois en République Fédérale d'Allemagne, París, Economica, 1982, pp. 64-78.

47 En la obra de Louis Favoreu y Loïc Philip, Les grandes décisions du Conseil Constitutitionnel, $7^{\text {a }}$. ed., Paris, Sirey, 1993, puede observarse el porcentaje significativo de instancias introducidas por los diputados y senadores de la oposición contra las leyes aprobadas por mayoría, antes de su publicación. 
de 1995, se encuentran legitimados para interponer dicha acción abstracta el equivalente al 33\% de los integrantes de la Cámara de Senadores, de la Asamblea Legislativa del Distrito Federal, así como de las legislaturas de los Estados. ${ }^{48}$ También se ha otorgado legitimación al Procurador General de la República, el cual está facultado para actuar como parte en la tramitación de esta acción de inconstitucionalidad, en virtud de la atribución ex officio que le confiere el párrafo tercero del Apartado A) del artículo $102^{\circ}$ constitucional.

58. Según la reforma constitucional de agosto de 1996, que admitió la impugnación de las leyes electorales por medio de la citada acción abstracta de inconstitucionalidad, se otorgó legitimación exclusivamente a las dirigencias nacionales estatales de los partidos políticos de acuerdo con la naturaleza de su registro (artículos $105^{\circ}$, fracción II, inciso f) de la Carta Federal y $62^{\circ}$ de la Ley Reglamentaria, reformados por decretos legislativos publicados los días 22 de agosto y 22 de noviembre de 1996, respectivamente). Este precepto fundamental dispone, además, que «la única vía para plantear la no conformidad de las leyes electorales a la Constitución es la prevista en este artículo".

59. Los citados incisos a) a e) de la mencionada fracción II del artículo $105^{\circ}$ constitucional establecen una relación directa de fracciones legislativas con el tipo de normas sujetas a control. En virtud de lo anterior, los integrantes de las Cámaras de Diputados y de Senadores del Congreso de la Unión podrán plantear la acción abstracta de las leyes federales y del Distrito Federal emitidas por el Congreso Federal, y los senadores también contra los tratados internacionales celebrados por el Ejecutivo federal y aprobados por la mayoría de dicha Cámara; los miembros de las legislaturas de los Estados contra las disposiciones normati-

48 Podemos señalar, de manera comparativa, que la legitimación para interponer la acción abstracta de inconstitucionalidad se confiere en Austria a un tercio de los diputados del Consejo Nacional; en Francia a sesenta diputados o el mismo número de senadores; en España, a cincuenta diputados o cincuenta senadores; en Alemania, a un tercio de los miembros del Parlamento federal; en Portugal, a un décimo de los diputados. El extremo está representado por la Constitución de Bolivia, en cuyo artículo $120^{\circ}$, inciso a), reformado en agosto de 1994 , se dispone que cualquier senador o diputado puede interponer la citada acción abstracta de inconstitucionalidad. Cfr. Héctor Fix Fierro, "La reforma judicial de 1994", cit. supra nota 45, pp. 115-117, y José Antonio Estrada Sámano «La inconstitucionalidad de leyes en la reforma judicial", en Revista de Investigaciones Juridicas de la Escuela Libre de Derecho, México, vol. 19,1995 , pp. 407-434. 
vas generales expedidas por dichos órganos, y los que forman parte de la Asamblea Legislativa del Distrito Federal, contra las leyes emitidas por la propia Asamblea. En relación con la impugnación directa de las leyes electorales, el inciso f) del citado precepto constitucional establece que las dirigencias nacionales pueden combatir leyes federales y locales, pero las estatales sólo pueden interponer la acción contra disposiciones de carácter local.

60. Una situación especial corresponde al Procurador General de la República en cuanto facultado para interponer dicha acción abstracta por la inconstitucionalidad de las leyes de carácter federal, estatal y del Distrito Federal, así como de los tratados internacionales (artículo $105^{\circ}$, fracción c) de la Constitución Federal).

61. El procedimiento se inicia con la demanda de acción de inconstitucionalidad que deberá interponerse dentro de los treinta días naturales contados a partir del día siguiente al de la publicación en el periódico oficial correspondiente de la ley o tratado internacional que pretende combatirse (artículo $105^{\circ}$, fracción II, de la Carta Federal y $60^{\circ}$ de la Ley Reglamentaria). Este último precepto establece que si el último día del plazo fuese inhábil, la demanda podrá presentarse el primer día hábil siguiente. Sin embargo, en la reforma a dicho artículo $60^{\circ}$ de noviembre de 1996, se agregó que en «materia electoral para el cómputo de los plazos todos los días son hábiles». ${ }^{49}$

49 Sobre la tramitación de las acciones de inconstitucionalidad, José Ramón Cossío Díaz, "Artículo $105^{\circ}$ " en Constitución Politica de los Estados Unidos Mexicanos. Comentada, 9a. ed., México, Porrúa-UNAM, 1997, pp. 1067-1062; Jorge Carpizo, José Ramón Cossío Díaz y Héctor Fix-Zamudio, "La jurisdicción constitucional en México", en Domingo García Belaunde y Francisco Fernández Segado (coords.), La jurisdicción constitucional en Iberoamérica, Madrid, Dykinson, 1997, pp. 771-775; Elisur Arteaga Nava, “Las nuevas facultades de la Suprema Corte de Justicia de la Nación", en Mario Melgar Adalid (editor) Reformas al Poder Judicial, México, UNAM, 1995, pp. 71-94; Tonatiuh García Castillo, La defensa de la Constitución. El articulo $105^{\circ}$ y el juicio constitucional, México, ASBE, 1997, pp. 115-121; Juventino V. Castro, El artículo $105^{\circ}$ constitucional, México, Porrúa, 1997, pp. 55-111; Olga Sánchez Cordero de García Villegas, "El artículo $105^{\circ}$ y sus reformas", en Excélsior, México, $1^{\circ}$ al 5 de octubre de 1995, primera edición; Héctor Fix-Fierro, "La defensa de la constitucionalidad en la reforma judicial de 1994" en La reforma constitucional en México y Argentina, México, UNAM, 1996, pp. 41-57, y José Ramón Cossío Díaz y Luis Manuel Pérez de Acha, "Análisis comparativo entre las controversias constitucionales y las acciones de inconstitucionalidad", en La Defensa de la Constitución, coordinada por dichos autores, México, Fontamara, 1996. 
62. Por lo que respecta a los fallos dictados por el Pleno de la Suprema Corte de Justicia, se adopta el principio de que si no fuesen aprobados por mayoría de ocho votos (respecto de once) dicho alto tribunal debe desestimar la acción ejercitada y ordenar el archivo del asunto (artículo $72^{\circ}$ de la Ley Reglamentaria). Esta disposición nos parece muy inconveniente, ya que en los ordenamientos en los que se ha establecido una votación calificada en este tipo de procesos constitucionales, se ha traducido en una grave limitación en su conocimiento, especialmente cuando se trata de cuestiones controvertidas, en las que generalmente se divide la votación. ${ }^{50}$

63. b) El juicio de revisión constitucional electoral. Este instrumento fue introducido por el artículo $99^{\circ}$ constitucional y por la Ley General de Medios de Impugnación en Materia Federal de 1996, con el objetivo de establecer la posibilidad de combatir la inconstitucionalidad de los actos o resoluciones de las autoridades electorales de las entidades federativas, si se toma en consideración que no existe otro procedimiento por el cual pudiesen combatirse los actos concretos de las autoridades electorales locales que infrinjan directamente la Constitución Federal, ya que no procede el juicio de amparo, según la jurisprudencia tradicional, contra la violación de los derechos políticos, ${ }^{51}$ y por el contrario, si

$50 \mathrm{El}$ ejemplo comparativo que conocemos se refiere a las Leyes Orgánicas del Tribunal de Garantías Constitucionales establecido por la Carta peruana de 1979, de 19 de mayo de 1982 (número 23,385) y del Tribunal Constitucional en la ley fundamental del mismo Perú, expedida en 23 de diciembre de 1994 y publicada el 10 de enero de 1995 (número 26,345). El porcentaje de votos para la declaración general de inconstitucionalidad era de 6 sobre 9, en el primer caso y de 6 respecto de 7 , en el segundo, lo que se ha traducido en una escasa actividad, en esta materia, de los citados tribunales, Cfr. FranciscoEguiguren Praeli, «Diez años de régimen constitucional en el Perú, 1980-1990", en Los retos de una democracia insuficiente, Lima, Comisión Andina de Juristas, 1990, p. 66 y ss.; Id., "El Tribunal de Garantías Constitucionales, las limitaciones del modelo y las decepciones de la realidad", en Lecturas sobre temas constitucionales, núm. 7, Lima, Comisión Andina de Juristas, 1991, pp. 48-58; Javier Valle Riestra, "El fracaso de la Constitución", en Lecturas constitucionales andinas, Lima, Comisión Andina de Juristas, 1992, pp. 20-23; Alberto Borea Odría, Las garantias constitucionales: hábeas corpus y amparo, Lima, Libros Peruanos, 1992, pp. 407-425, y Samuel Abad Yupanqui, "La jurisdicción constitucional en la carta peruana de 1993: antecedentes balances y perspectivas, en Una mirada a los tribunales constitucionales. Las experiencias recientes, Lima, Comisión Andina de Juristas, -Konrad Adenauer Stiftung, 1995, pp. 192-198.

51 Todavía se encuentra vigente el criterio de la jurisprudencia de la Suprema 
pueden impugnarse las disposiciones legislativas electorales locales por conducto de la acción abstracta de inconstitucionalidads. ${ }^{52}$

64. En la parte relativa de la exposición de motivos de la iniciativa presidencial que sirvió de base a las reformas constitucionales de agosto de 1996, se manifestó que:

«[...] al respecto la iniciativa plantea un mecanismo absolutamente respetuoso de nuestro sistema federal, al prever que esta nueva vía sólo procederá cuando haya violaciones directas a la Constitución Federal y en casos determinados que por su trascendencia ameriten ser planteados ante esta instancia jurisdiccional. Con lo anterior se pretende moderar aquellas situaciones que por su disparidad o divergencia con el sentido de nuestro texto fundamental, atentan contra nuestro Estado de Derecho. De igual manera, con esta vía se aspira a superar los debates sobre la legalidad de los procesos locales, cerrando el camino a decisiones políticas sin fundamento jurídico que pueden afectar el sentido de la voluntad popular expresada en las urnas [...].»

65. En efecto, de acuerdo con lo establecido por el artículo $86^{\circ}$ de la ley mencionada, el juicio de revisión constitucional electoral sólo procederá para impugnar actos o resoluciones de las autoridades competentes de las entidades federativas para organizar y calificar los comicios locales o resolver las controversias que surjan durante los mismos, pero siempre que se satisfagan determinados requisitos, cuyo incumplimiento determinará que se deseche de plano el medio de impugnación respectivo. En tal virtud, el citado ordenamiento exige que los actos o resoluciones combatidos tengan, en primer lugar, el carácter de definitivos y firmes; que violen algún precepto de la Constitución Federal; que la violación reclamada pueda ser determinante para el desarrollo del proceso electoral respectivo o el resultado final de las elecciones; que la reparación

Corte de Justicia, que se estableció desde el siglo anterior, en el sentido: Derechos politicos. Improcedencia. La violación de los derechos políticos no da lugar al juicio de amparo, porque no se trata de garantías individuales". tesis 623, Apéndice al Semanario Judicial de la Federación, México, 1988, tesis comunes al pleno y a las salas, t. II, p. 1061.

52 Cfr. María Macarita Elizondo Gasperín, "El juicio de revisión constitucional", en Estudio teórico práctico de medios de impugnación en materia electoral, cit. supra nota 33, pp. 283-310. 
solicitada sea material y jurídicamente posible dentro de los plazos electorales y factible antes de la fecha constitucional o legalmente fijada para la instalación de los órganos o la toma de posesión de los funcionarios electos, $y$ finalmente, que se hubiesen agotado en tiempo y forma todas las instancias previas establecidas por las leyes para combatir los actos o resoluciones electorales en virtud de los cuales pudieran haberse modificado, revocado o anulado.

66. El conocimiento de este proceso de revisión constitucional corresponde a la sala superior del Tribunal Electoral del Poder Judicial de la Federación, en única instancia, tratándose de actos o resoluciones relativos a las elecciones de gobernadores, diputados locales, autoridades municipales, así como de Jefe de Gobierno, diputados a la Asamblea Legislativa y titulares de los órganos político-administrativos del Distrito Federal (artículos 99 $9^{\circ}$, fracción IV de la Constitución Federal; $189^{\circ}$, fracción I, inciso e) de la ley Orgánica del Poder Judicial de la Federación y $87^{\circ}$, de la Ley General del Sistema de Medios de Impugnación en Materia Electoral).

67. Únicamente los partidos políticos pueden promover dicho juicio de revisión constitucional electoral por conducto de sus representantes legítimos, siempre que esos representantes estén registrados formalmente ante el órgano electoral responsable cuando éste haya dictado el acto o resolución impugnados; cuando hayan interpuesto el medio de impugnación jurisdiccional al cual recayó la resolución combatida; los que hayan comparecido con el carácter de tercero interesado en el medio de impugnación jurisdiccional al cual recayó la resolución reclamada, o finalmente, los que tengan facultades de representación de acuerdo con los estatutos del partido político respectivo, en los casos que sean distintos a los precisados en los supuestos anteriores. La falta de legitimación o de personería será la causa para el desechamiento de plano del proceso impugnativo de que se trata (artículo $88^{\circ}$ de la Ley General de Medios de Impugnación).

68. La Ley General de Medios de Impugnación en Materia Electoral establece algunas modalidades especiales para la tramitación de este juicio de revisión constitucional contra actos y resoluciones de las autoridades electorales locales, las cuales: a) una vez que reciban el escrito por el cual se promueva el juicio, lo remitirán de inmediato a la sala superior del tribunal Electoral, con todos sus anexos, el expediente completo en el cual se hubiese dictado el auto o resolución combatidos, y su informe 
que deberá contener los motivos y fundamentos jurídicos que considere pertinentes para sostener la constitucionalidad de los citados acto o resolución que se reclama; b) dentro del plazo de setenta y dos horas en que debe darse a conocer públicamente la impugnación (artículo $17^{\circ}$, inciso b) de dicho ordenamiento), el o los terceros interesados podrán formular los alegatos que consideren pertinentes, que, en el caso de que se presenten, deben ser enviados a la citada sala superior y se informará a la misma de la conclusión del mencionado plazo y la comparecencia de los terceros interesados; c) en el juicio no se podrá ofrecer o aportar prueba alguna, salvo en los casos extraordinarios de pruebas supervinientes, cuando éstas sean determinantes para acreditar la violación reclamada y d) finalmente, recibida la documentación en el Tribunal Electoral, el presidente de la sala superior turnará de inmediato el expediente al magistrado que corresponda para que formule el proyecto de resolución respectivo (artículos $89^{\circ}-92^{\circ}$ de la Ley General del Sistema de Medios de Impugnación).

69. El artículo $93^{\circ}$ de la referida ley consigna reglas particulares respecto de los efectos de las sentencias que decidan los juicios de revisión constitucional electoral, ya que dichos efectos pueden consistir en la confirmación del acto o de la resolución impugnados, o bien, en la revocación o modificación de los mismos, y consecuentemente, en el establecimiento de los medios necesarios para reparar la violación constitucional que se hubiese cometido. ${ }^{53}$

53 Como un ejemplo de la efectividad de este proceso de revisión constitucional, pueden citarse los juicios promovidos por el Partido de la Revolución Democrática contra las resoluciones del Consejo Electoral del Estado de Yucatán de 24 de mayo de 1998, y de las decisiones del Pleno del Tribunal Electoral de Estado de 17 de junio siguiente que desechó los recursos de inconformidad interpuestos por dicho Partido contra las resoluciones mencionadas, las que fueron modificadas por el Tribunal Electoral del Poder Judicial de la Federación, con fecha 30 de junio de ese año, al día siguiente de su recepción y dicho Tribunal también resolvió los incidentes de inejecusión de sentencia, por fallos de 7 de julio, en que se declaró improcedente declarar incjecutables dichas sentencias. Cfr. Tribunal Electoral del Poder Judicial de la Federación, Ejecución de sentencias en los juicio de revisión constitucional electoral (Caso Yucatán), México, 1998. 


\section{Conclusiones}

70. Con apoyo las breves reflexiones anteriores, podemos llegar a las siguientes conclusiones:

71. Primera. La participación activa de la oposición política en los regímenes de la Democracia liberal de nuestra época ha sido objeto de estudio predominantemente por los cultivadores de la ciencia política, pero han sido escasos los análisis de carácter jurídico, particularmente en los ordenamientos latinoamericanos, y en especial en el régimen constitucional mexicano, por lo que resulta conveniente realizar un estudio, así sea preliminar, sobre esta significativa cuestión que asume de manera creciente una especial importancia.

72. Segunda. Ha sido paulatino el desarrollo de lo que se puede calificar como el estatuto constitucional de la oposición política, ya que según lo expresado certeramente por el constitucionalista italiano Giuseppe de Vergottini dicha regulación ha pasado por tres etapas lógicas no forzosamente históricas: "disentimiento", "límite», "alternativa", es decir, se ha caminado de la prohibición y represión, a la tolerancia y finalmente a la plena aceptación de la participación activa de los sectores políticos que no se encuentran en el gobierno, a los que se han atribuido directa o indirectamente un conjunto de prerrogativas que han conducido a un régimen de "oposición garantizada", terminología propuesta por el mismo profesor Vergottini y que ha tenido una gran aceptación en la doctrina contemporánea.

73. Tercera. Un primer paso en el reconocimiento de la función constitucional de la oposición estuvo conformado con la constitucionalización de los partidos políticos a los cuales se les confirieron varios derechos relativos a su registro, el acceso a los medios de comunicación social y al financiamiento público, con el objeto de lograr un mayor equilibrio entre los diversos partidos. Esto trajo como consecuencia el reconocimiento de prerrogativas para aquellos que se encuentran fuera del gobierno.

74. Cuarta. El reconocimiento de atribuciones específicas para la oposición se efectuó primero en el régimen constitucional británico por medio de costumbres y convenciones y finalmente por la legislación que se inició con la Minister of the Crown Act de 1937, y otros ordenamientos posteriores que confirieron al líder del partido que no logró vencer en las elecciones anteriores (en un sistema predominante- 
mente bipartidista) la categoría oficial de Jefe de la Oposición, con la facultad de designar a sus colaboradores que constituyen el denominado Shadow Cabinet. Este sistema se extendió a otros países de la Commonwealth, tales como Australia, Canadá y Nueva Zelandia, así como algunos Estados de la República Federal de Alemania, por otra parte se han establecido lineamientos constitucionales para configurar un estatuto de la oposición en las Cartas Fundamentales de Portugal, Colombia y Ecuador.

75. Quinta. Por lo que se refiere al ordenamiento mexicano, la carta Federal vigente de 1917 no reguló, debido a la época en que fue expedida a los partidos políticos, comprendidos en las leyes electorales, ya que dichos partidos fueron elevados a instituciones constitucionales en la segunda posguerra. Por otra parte, después de varias décadas de predominio de un partido de carácter hegemónico establecido en 1929, con un sistema electoral deficiente de mayoría, el primer paso importante hacia el fortalecimiento de las agrupaciones políticas de oposición se dio en la reforma electoral de diciembre de 1977, por la cual se modificaron varios preceptos fundamentales para constitucionalizar a los partidos políticos e introducir para los minoritarios un sistema de representación proporcional, que se perfeccionó de manera creciente en las subsecuentes reformas al texto de Ley Fundamental en 1986, 1990, 1993 y 1996.

76. Sexta. Si bien no se ha establecido de manera expresa en México un estatuto constitucional para la oposición, las diversas reformas constitucionales posteriores a la de diciembre de 1977 han permitido el fortalecimiento de los entonces muy débiles partidos políticos que no accedían al Gobierno debido al absoluto predominio del entonces partido hegemónico. Indirectamente podemos considerar a los preceptos constitucionales sobre partidos políticos y régimen electoral, como un estatuto de la oposición en el ordenamiento mexicano. En esta dirección pueden señalarse las disposiciones relativas al sistema electoral mixto, de mayoría y de representación proporcional, el acceso de los partidos y agrupaciones políticas a los medios de comunicación social, el otorgamiento de un financiamiento público, un registro electoral confiable, así como el desarrollo de la autonomía e independencia de los organismos administrativos que organizan los procedimientos electorales y la creación de tribunales independientes para resolver conflictos electorales.

77. Séptima. En las reformas constitucionales de 1994 y 1996, se introdujeron dos instrumentos procesales que se traducen en prerroga- 
tivas para los partidos y agrupaciones políticas de oposición. El primero es la acción abstracta de inconstitucionalidad que pueden interponer el $33 \%$ de las fracciones parlamentarias contra las disposiciones legislativas aprobadas por mayoría (artículo $105^{\circ}$ constitucional fracción II), y el segundo, el juicio de revisión constitucional electoral contra las decisiones definitivas de los organismos electorales de las entidades federativas (artículo $99^{\circ}$ de la Carta Federal).

78. Octava. Todos estos instrumentos se han traducido en la práctica de una vigorización evidente de los partidos de oposición que ha resultado en un régimen pluralista que se ha consolidado de manera paulatina. En efecto, en las elecciones para diputados federales de julio de 1997 , el Partido Revolucionario Institucional perdió su tradicional mayoría absoluta, ya que sólo obtuvo el $47.8 \%$ de los sufragios, por lo que el mayor número de las curules pertenecen en su conjunto a los partidos de oposición. Además la misma oposición ha obtenido la titularidad del Gobierno, de las diputaciones y de los municipios en varias entidades federativas.

79. Novena. Se requiere ahora que se establezca la regla que consagran numerosos ordenamientos contemporáneos, es decir la exigencia de la democracia interna de los partidos políticos, como lo señala certeramente el destacado constitucionalista mexicano Diego Valadés Ríos. En la práctica se observa que los partidos políticos han iniciado la modificación del sistema tradicional de decisiones verticales y han organizado recientemente convenciones primarias para designar a los candidatos para los gobiernos locales y al parecer este procedimiento se perfeccionará en las elecciones federales del año 2000 para la selección de candidatos a la Presidencia de la República, ya que en dichos sufragios habrá una competencia equilibrada que no se había presentado con anterioridad. 